\title{
XRD and FT-IR investigations of sub-bituminous Assam coals
}

\author{
BINOY K SAIKIA*, R K BORUAH ${ }^{\dagger}$ and P K GOGOI ${ }^{\ddagger}$ \\ Department of Chemical Sciences, Tezpur University, Tezpur 784 028, India \\ ${ }^{\dagger}$ Analytical Chemistry Division, Regional Research Laboratory, Jorhat 785 006, India \\ ${ }^{\ddagger}$ Department of Chemistry, Dibrugarh University, Dibrugarh 786 004, India
}

MS received 8 February 2007; revised 19 June 2007

\begin{abstract}
Two coal samples collected from Makum coal field, Assam, India were studied by XRD and FT-IR techniques. The X-ray diffractogram shows the existence of some crystalline carbons in Assam coals as proven by the appearance of peaks. The radial distribution functional (RDF) method was applied for the determination of structural aspects of the coals. The study indicates that the coals are lignite in type and there is no evidence of graphite-like structures. The maximum in the $G(r)$ plots of function of radial distribution of atoms (FRDA) relates to different distances between carbon atoms of aliphatic chains. The first significant maximum relates to the $\mathrm{C}-\mathrm{C}$ bond (type $\mathrm{C}-\mathrm{CH}=\mathrm{CH}-\mathrm{C}$ ), the second maximum relates to the distance between carbon atoms of aliphatic chains that are located across one carbon atom. The curve intensity profiles obtained from FRDA show quite regular molecular packets for this coal. The coals were found to be lignite in nature. FT-IR study shows the presence of aliphatic carbon, $\mathrm{C}=\mathrm{O}$ and $\mathrm{C}-\mathrm{O}$ stretching associated with $-\mathrm{OH}$ and $-\mathrm{NH}$ stretching vibrations. Kaolinite and quartz were also found to be major minerals in Assam coals by FTIR spectroscopy. The difference in intensities of carbonyl groups of the coal samples is likely to relate with the rank.
\end{abstract}

Keywords. Assam coal; coal structure; RDF of coal.

\section{Introduction}

Coal is a heterogeneous, combustible, sedimentary carbonaceous material found in Earth crust in many parts of the world (Gorbaty and Ouchi 1981; Myers 1982; Haenel 1992). It also contains other elements such as nitrogen, sulphur and traces of mineral matter. This is one of the most plentiful resources of conventional energy and it forms the backbone of the modern industrial civilization. Although coal has been utilized for several years, the exact chemical nature of its structure are still not fully known (Marzec 2002). The structural properties of coal have been receiving much attention among coal chemists because of their importance in chemical reactivity during various utilizations. Detailed structural characterization has been found to be extremely difficult and therefore, research on coal structure is still a challenging task and continues to be pursued intensively. The investigation of the chemical structure of coal has led to comprehensive and well-defined results on the basis of development of spectroscopic methods. These are FTIR, UV-visible spectroscopy, X-ray structural analysis, solid state NMR etc. X-ray diffraction studies provide useful information about the internal arrangement of atoms in coal (Haenel 1992). Coals of different age have different chemical compositions, and therefore, different structures.

*Author for correspondence (binoyrrl@yahoo.com)
Even within a certain age group (rank) of coal, such as lignites or bituminous coals, the structure may vary depending on the environment in which a particular coal was formed.

X-ray diffraction from coal has been a subject of study among many several present and past workers (Grigoriew 1990; Alvarez et al 1998; Wertz 1998; Saikia et al 2005; Maity and Mukharjee 2006). The first basic X-ray diffraction studies on coal structure were carried out many years ago by using simple data processing (Nelson 1954; Cartz et al 1956; Diamond 1958). Blayden et al (1944) postulated that coal contains some aromatic layers aligned parallel to near neighbours at a distance of about $3.5 \AA$. Hirsch (1954) indicated that coal (up to about 90\% C) contained an appreciable proportion of small layers consisting of one to three rings. In addition, Cartz and Hirsch (1960) stated that these small condensed aromatic regions form part of layer units which may themselves be linked to other such units by aliphatic or alicyclic materials fivemembered rings to form large bucked sheets. Radial distribution function (RDF), obtained from Fourier transform of molecular scattering, has been used to examine the molecular-level structuring of coals by different workers (Cartz and Hirsch 1960; Schoening 1982, 1983; Wertz and Bisell 1994, 1995).

The study on structure of coal was carried out in India very early, which showed the aromatic layered structure in coals (Mahadevan 1929, 1930; Mitra 1953). The detailed 
spectroscopic studies carried out on Indian coals have not been reviewed as yet as per our literature survey. Not much X-ray diffraction and spectroscopic work has been done on Assam coals although extensive research works were carried out on different aspects (Barooah and Baruah 1996; Baruah et al 2006), particularly sulphur problem and trace metals of coal. But few have shown interest in completely understanding the structural features of Assam coals, which has relations with the chemistry of coal that became the topic of research in recent years (Iino 2002; Kashimura et al 2004). Thus, a basic knowledge of coal structure is crucial to an understanding of the physical properties of coal and chemistry of conversion processes such as gasification, liquefaction, combustion, carbonization and desulphurization. There is still only little basic information concerning the structure of Assam coal. Assam coals have been classified as sub-bituminous on the basis of the studies on their chemical compositions and physical characteristics (Myers 1981). Because of its high sulphur content, it has to be blended with other auxiliary fuels such as natural gas or imported coals to satisfy the energy requirement in the power plant and the limitation on sulphur and nitrogen oxide emission to the atmosphere. It is to be noted that low-grade coal, ranging from lignite to sub-bituminous are exclusively used in combustion to generate electric power. It is from this point of view that the present investigation is directed to some aspects of structural studies of Assam coal by X-ray diffraction and FTIR spectroscopy.

In this study, some aspects of structural investigation of two Assam coals were discussed by the radial distribution functional studies, which is, therefore, independent of any assumptions about the presence and structure of crystalline region in coal. Although the removal of mineral matter component is desirable, it is not essential in the present case because the parameter is based on a very small region of radial distribution function thereby greatly reducing the probability of interference from the mineral component (Schoening 1983). Radial distribution functions (RDF) have been used frequently in different investigations of coal (Ruland 1968). Assam coals have not yet been attempted for structural investigation by using XRD.
Thus, this paper attempts to analyse the structure of Assam coal by RDF technique using X-ray diffraction data for the first time.

\section{Experimental}

Freshly mined coal samples were collected from Baragolai and Tipong collieries of Makum coal field, Assam, India. Makum coal field lies between latitudes $27^{\circ} 13^{\prime}-27^{\circ} 23^{\prime} \mathrm{N}$ and longitudes $95^{\circ} 35^{\prime}-96^{\circ} 00^{\prime} \mathrm{E}$ in the Tinisukia district of Assam, India. The samples were ground to $-200 \mathrm{BS}$ (sizes) before using for FT-IR, XRD and other chemical analyses.

\subsection{Physico-chemical analysis of coal samples}

The proximate analyses of the coal samples were done by standard methods (IS: 1350 (Part I) 1984). The elements $\mathrm{C}, \mathrm{H}$ and $\mathrm{N}$ were analysed by an elemental analyser, Perkin Elmer, model 2400, total sulphur was determined by Eshcka method (Himus 1954) and the percentage of oxygen was calculated by the difference. The forms of sulphur were determined by following standard methods (ASTM D 2492). The calorific values were determined by using Bomb calorimeter (ASTM D 3286). The analyses of the coal samples are given in table 1 . The ash analysis of the coal samples was carried out by standard methods (Vogel 1969; Karr 1978b) and reported in table 2. All analyses for the samples were carried out in quadruplicate and mean values have been reported. The FTIR of the original coal samples are recorded by Perkin Elmer system 2000, Model 640B using KBr pellet.

\section{$2.2 X$-ray diffraction data collection and treatments}

The samples were properly washed with sufficient distilled water for maximum removal of mineral matter. Diffraction data were obtained using computer controlled X-ray Diffractometer Type XPERT PRO (PHILIPS). Start angle: 3.015, target: $\mathrm{Cu}$ (Fe-filtered), stop angle: 100, measuring

Table 1. Chemical analysis of coal samples (as received basis, \%wt).

\begin{tabular}{|c|c|c|c|c|c|c|c|c|c|c|c|c|c|c|}
\hline Coal & Ash & Moisture & $\begin{array}{l}\text { Volatile } \\
\text { matter }\end{array}$ & $\begin{array}{l}\text { Fixed } \\
\text { carbon }\end{array}$ & $\begin{array}{l}\text { Pyritic } \\
\text { sulphur }\end{array}$ & $\begin{array}{l}\text { Sulphate } \\
\text { sulphur }\end{array}$ & $\begin{array}{l}\text { Organic } \\
\text { sulphur }\end{array}$ & $\begin{array}{l}\text { Total } \\
\text { sulphur }\end{array}$ & $\mathrm{C}$ & $\mathrm{H}$ & $\mathrm{N}$ & $\mathrm{O}$ & $\mathrm{H} / \mathrm{C}$ & $\mathrm{O} / \mathrm{C}$ \\
\hline Baragolai & $5 \cdot 70$ & $2 \cdot 40$ & 47.40 & $44 \cdot 50$ & 0.61 & 0.53 & $4 \cdot 16$ & $5 \cdot 30$ & $75 \cdot 4$ & $5 \cdot 53$ & $0 \cdot 89$ & $12 \cdot 48$ & 0.07 & $0 \cdot 17$ \\
\hline Tipong & $7 \cdot 90$ & $3 \cdot 20$ & $43 \cdot 50$ & 45.40 & $0 \cdot 31$ & 0.51 & $3 \cdot 32$ & $4 \cdot 14$ & $76 \cdot 0$ & $5 \cdot 23$ & $1 \cdot 10$ & 9.77 & $0 \cdot 11$ & $0 \cdot 13$ \\
\hline
\end{tabular}

Table 2. Ash compositions of coal samples (\%wt).

\begin{tabular}{lcccccccc}
\hline Coal & $\mathrm{SiO}_{2}$ & $\mathrm{Fe}_{2} \mathrm{O}_{3}$ & $\mathrm{MgO}$ & $\mathrm{CaO}$ & $\mathrm{SO}_{3}$ & $\mathrm{TiO}_{2}$ & $\mathrm{Al}_{2} \mathrm{O}_{3}$ & Others \\
\hline Baragolai & 60.6 & 21.8 & 1.7 & 0.7 & 0.4 & 1.2 & 10.0 & 3.6 \\
Tipong & 56.7 & 17.4 & 1.1 & 1.7 & 1.2 & 1.0 & 16.2 & 4.7 \\
\hline
\end{tabular}


time: $0 \cdot 5$, step angle: 0.03 and data processing condition: smoothing points, goniometer radius (R): $240 \mathrm{~mm}$, equatorial angle subtended at the specimen by the detector slit $(\beta): 1^{\circ}$. The observed experimental intensities were corrected for air scatter, absorption and polarization by the sample by using the formulae given elsewhere (Klug and Alexander 1974) as summarized below.

2.2a Correction for air scatter: For the symmetrical reflection in diffractometry the correction for air scatter is given by

$$
a_{\mathrm{r}}=1 / 2+(1 / 2-T \cos \theta / R \beta) \exp (-2 \mu T / \sin \theta),
$$

where $a_{\mathrm{r}}$ is the ratios of the air scattered intensity received with and without the sample, $R$ the goniometer radius, $\beta$ the equatorial angle subtended at the specimen by the detector slit, $T$ the thickness of the flat specimen and $\mu$ the absorption coefficient.

$2.2 \mathrm{~b}$ Correction for absorption by sample for symmetrical reflection: This correction for the sample is performed by

$$
I / I_{\mathrm{T}}=[1-\exp (-2 \mu T \cos \theta)]^{-1},
$$

where $I_{\mathrm{T}}$ is the observed intensity, $I_{\alpha}$ the intensity corresponding to specimen of effectively infinite thickness, $T$ the thickness of the flat specimen and $\mu$ the absorption coefficient.

2.2c Correction for polarization: For crystal-monochromatized radiation a ray scattered by the sample is diminished in intensity by the factor

$$
P=\frac{1+\cos ^{2} 2 \theta^{\prime} \cos ^{2} 2 \theta}{1+\cos ^{2} 2 \theta^{\prime}},
$$

where $\theta^{\prime}$ is the Bragg angle for the reflection planes of the monochromatic crystal. Thus, for the (200) planes of sodium chloride $\cos ^{2} 2 \theta^{\prime}$ is 0.723 for $\mathrm{CuK} \alpha$ radiation. Hence, the observed intensities should be normalized to the un-polarized reference level by multiplying them by the reciprocal of equation above.

\subsection{Determination of radial distribution function (RDF) for Assam coals}

X-ray diffraction provides the atom sizes and arrangement in solid state. In most diffraction and certain theoretical investigation of matter, knowledge of structure is sought, and such knowledge is frequently displayed as a distribution function giving the probability of finding of a pair of atoms in a given configuration. The pair distribution function may be represented as $p\left(r_{1} \cdot r_{2}\right)$, which gives the probability of simultaneously finding atom 1 in a unit volume located at $r_{1}$ and atom 2 in a unit volume at $r_{2}$. By placing the coordinate system's origin on an atom and integrating over the space accessible to that kind of atom, a distribution function, $p\left(r_{2}-r_{1}\right)$ is obtained.
The RDF for coal samples may be evaluated by using the methods given elsewhere (Klug and Alexander 1974) using the following relations,

$$
\begin{aligned}
& 4 \pi r^{2} \rho(r)=4 \pi r^{2} \rho_{0}+\frac{2 r}{\pi} \int_{0}^{\infty} \operatorname{Si}(S) \sin r S \mathrm{~d} s, \\
& \operatorname{Si}(S)=\frac{I}{N f^{2}}-1,
\end{aligned}
$$

where $S$ is defined as $4 \pi \sin \theta / \lambda, \rho(r)$ the number of atoms per unit volume at a distance, $r$, from the reference atom, $\rho_{0}$ the mean atomic density, $N$ the Avogadro's number and $f$ the scattering factor for carbon atom.

Then the RDF $\left[4 \pi r^{2} \rho(r)\right]$ and atomic pair distribution function $\left[4 \pi r^{2}\left\{\rho(r)-\rho_{0}\right\}\right]$ plots for the coals were evaluated using the corrected diffraction intensities obtained in this study using the methods given elsewhere (Klug and Alexander 1974). A new computer program in $\mathrm{C}++$ was developed for the evaluation of radial distribution function of coal samples.

\section{Results and discussion}

\subsection{Physico-chemical analysis}

Tables 1 and 2 demonstrate the physico-chemical properties of 4 coal samples from different collieries of Assam, India. The coals are high sulphur in nature as seen from their sulphur contents, where sulphur is mainly organically bound. The inorganic forms of sulphur are low in Assam coals. Baragolai coal has the highest sulphur content with a value of 5.30 (\%wt), which in turn is low in ash content $(5.70 \% \mathrm{wt})$. The percentage of ash is of significance in the usefulness of coals. On the other hand, the highest ash containing Tipong coal has lower sulphur content with a value of $4 \cdot 14$ (\%wt). The composition of ash varies with the rank of coal and in some cases, variations are observed in the same seam. Due to its drift origin, Indian coals, in general, are of high ash content and the major constituents of ash are silica $\left(\mathrm{SiO}_{2}\right)$, alumina $\left(\mathrm{Al}_{2} \mathrm{O}_{3}\right)$ and iron oxide. Ash compositions of the coal samples are compared in table 2 . The ash composition also reflects the usefulness of the coal. All coal samples have the highest percentage of $\mathrm{SiO}_{2}$ followed by $\mathrm{Fe}_{2} \mathrm{O}_{3}$ or $\mathrm{Al}_{2} \mathrm{O}_{3}$. The other forms of oxides in ash include $\mathrm{Na}_{2} \mathrm{O}, \mathrm{K}_{2} \mathrm{O}$ etc. The $\mathrm{H} / \mathrm{C}$ was found to be 0.07 and 0.11 for Baragolai and Tipong coals, respectively. The $\mathrm{O} / \mathrm{C}$ ratios for the coals were found to be approximately same with 0.17 and 0.13 for Baragolai and Tipong coals, respectively.

\subsection{Radial distribution functional (RDF) analysis of coals}

The X-ray diffraction profiles of coals indicate that they are amorphous in nature (figure 1). The obtained radial 
distribution function (RDF) and atomic pair distribution function $[G(r)]$ plots for Baragolai and Tipong coals are shown in figures 2 and 3. Structural determination based on RDF fall into two main categories. In the first category, the RDF yields the mean distribution of interatomic distances of carbons and in the second category the structure of coal is determined. In either category, deductions about structure are based on the peak position and areas in the RDF. The RDF provides meaningful information about the mean number of nearest neighbours and their mean distances of approaches, and in certain cases intramolecular configuration may be deduced. Although in the later case, configuration of structure is attained by agreement between observed intensity and that calculated on the basis of some model (Kruh 1962). Table 3 shows the number of nearest neighbours (concentration of atoms) at different distances in coal matrix and graphite. These distances also signify the inter-atomic distances in a single layer of coal obtained from the RDF curves (figure 2). The

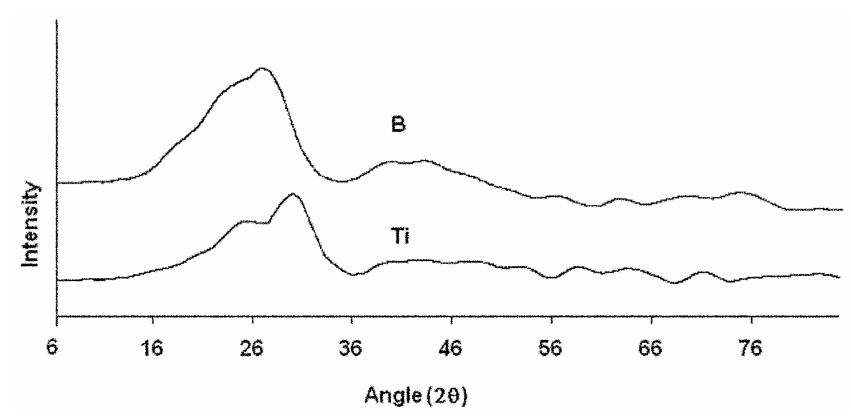

Figure 1. X-ray diffractogram of Baragolai (B) and Tipong (Ti) coal samples.

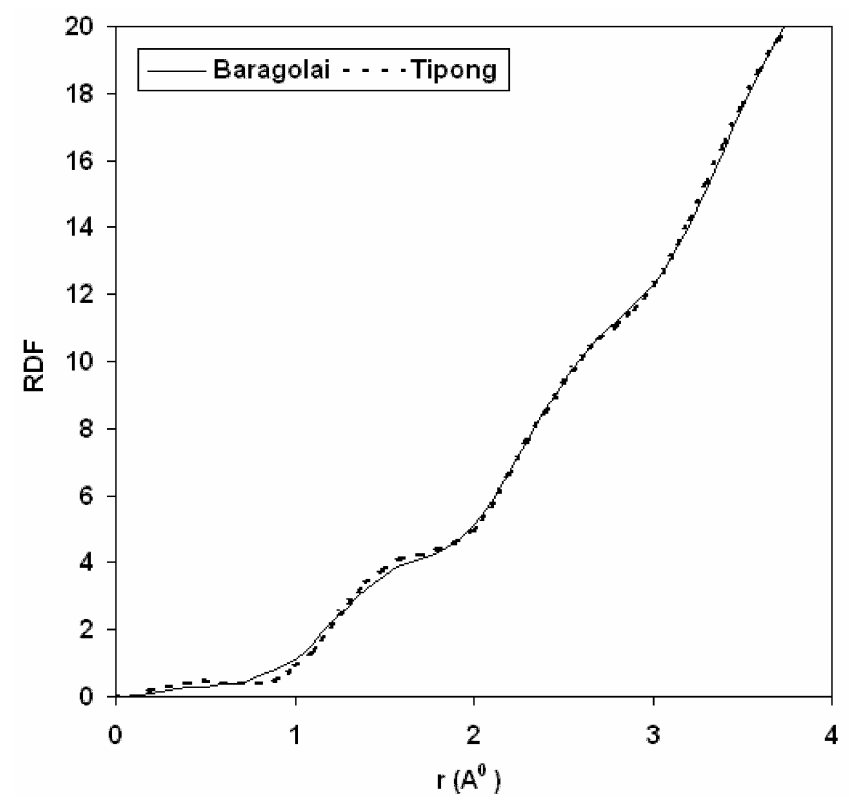

Figure 2. RDF of Baragolai and Tipong coal samples. coal samples show some concentrations of atoms at a distance of 0.4 and $0.5 \AA$ as shown in table 3 . Grigoriew (1990) in his study of coal vitrinite with about the same chemical composition found no interatomic distance of $0.4 \AA$. This indicates that the 0.4 or $0.5 \AA$ distance comes from non-vitrinite portion of the coal. Baragolai coal shows a little similarity with the graphite-like structure. It has 3 nearest neighbours at a distance of $1.4 \AA$, which is quite similar with the nearest neighbour of graphite structures at a distance of $1.42 \AA$ (table 3 ). The absence of the interatomic distance of $1.42 \AA$ in coal samples indicates the absence of graphite like arrangement of carbons in coal. Thus, the layers present in these coals are not graphitelike in their internal coordination system, which can also be attributed from the average $\mathrm{C}-\mathrm{C}-\mathrm{C}$ valence angle. This angle may be estimated from the RDF by

$$
\phi=\cos ^{-1}\left[p_{2}^{2}-2 p_{1}^{2}\right] / 2 p_{1}^{2} \text {. }
$$

Using $p_{1}=0.4$ (or 0.5 ) and $p_{2}=1.4$ (or 1.5 ), $\phi$ is found to be $>180^{\circ}$ which is very unlikely. Therefore, it may be concluded that the coals are lignite in type and contain no evidence of graphite-like structure. This can be compared with the lignite type of coal of different localities already reported (Elliot 1981). It may be mentioned here that the compositional differences like elemental composition, volume of vitrinite, mineral matters etc between these coals lead to differences in the RDF plots.

Figure 3 shows the comparison of $G(r)$ curves of the two coal samples from different collieries of Assam. The first significant maximum in the plots of Tipong coals was found to be at $r=0.15 \mathrm{~nm}$, whereas it was $r=0.14 \mathrm{~nm}$ for Baragolai coal which relates to the $\mathrm{C}-\mathrm{C}$ aliphatic bond length. The second maximum was found to appear at $r=0.27 \mathrm{~nm}$ for Baragolai coal and $r=0.26 \mathrm{~nm}$ for Tipong, respectively. These relate to the distance between carbon atoms of aliphatic chains that are located across one carbon atom. Further, the third maximum for Baragolai coal

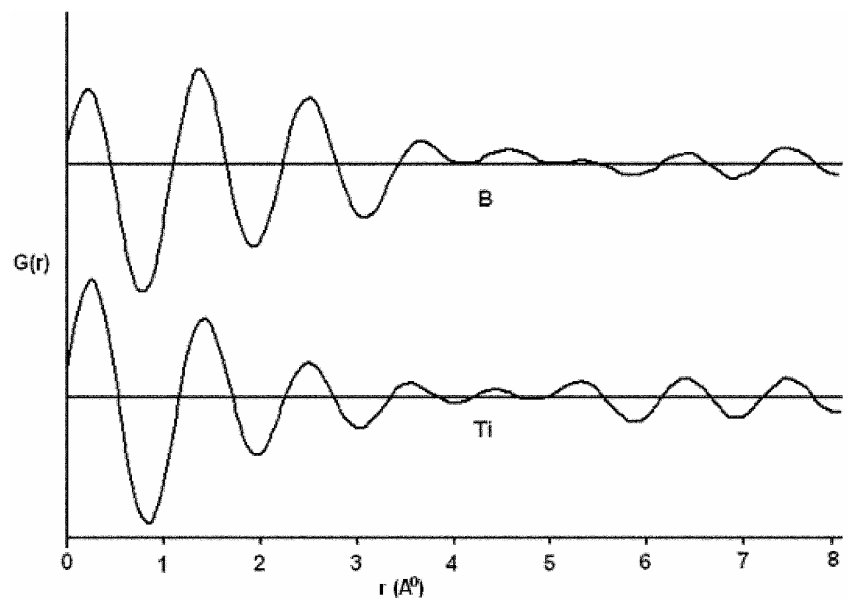

Figure 3. Plot for pair distribution function for the coal samples (B: Baragolai and Ti: Tipong coals). 
Table 3. Inter-atomic distances $(\AA)$ in a single layer of the two Assam coals and graphite structure.

\begin{tabular}{|c|c|c|c|c|c|}
\hline \multicolumn{2}{|c|}{ Baragolai } & \multicolumn{2}{|c|}{ Tipong } & \multicolumn{2}{|c|}{ Graphite } \\
\hline Distance $(\AA)$ & $\begin{array}{l}\text { Number of } \\
\text { neighbours }\end{array}$ & Distance $(\AA)$ & $\begin{array}{l}\text { Number of } \\
\text { neighbours }\end{array}$ & Distance $(\AA)$ & $\begin{array}{l}\text { Number of } \\
\text { neighbours }\end{array}$ \\
\hline $0 \cdot 4$ & - & 0.4 & - & - & - \\
\hline 1.4 & 3 & 1.5 & $3 \cdot 8$ & 1.42 & 3 \\
\hline $2 \cdot 7$ & 10 & $2 \cdot 6$ & 10 & $2 \cdot 46$ & 6 \\
\hline $3 \cdot 8$ & 21 & 3.6 & 19 & $2 \cdot 86$ & 3 \\
\hline $4 \cdot 6$ & 30 & $4 \cdot 6$ & 30 & 3.75 & 6 \\
\hline $5 \cdot 6$ & 45 & 5.4 & 41 & 4.25 & 6 \\
\hline- & - & - & - & 4.92 & 6 \\
\hline- & - & - & - & $5 \cdot 11$ & 6 \\
\hline
\end{tabular}

at $r=0.38 \mathrm{~nm}$ and for Tipong coal at $r=0.36 \mathrm{~nm}$ were also found, which is related to the distance between carbon atoms of aliphatic chains located across two carbon atoms. These two coals show a maxima at similar positions of $r=0.46 \mathrm{~nm}$. This value is found to be similar with the distance between parallel aliphatic chains of oriented polyethylene (Vasin and Gladyshera 1983). The curve intensity profiles of $G(r)$ clearly show quite regular molecular packets for these coals. These two high sulphur Assam coals have almost the same RDF inter-atomic distances except slight differences. The slight differences in the inter-atomic distances for coals are attributed to their difference in contents of clay minerals like illite, quartz and chlorite.

\subsection{FTIR spectroscopic study of coals}

Fourier transform infrared (FTIR) spectroscopy is a powerful tool for characterization of coal and its products as it furnishes fast comprehensive view about the structure/ composition of the materials. Figure 4 shows FTIR spectra of the two coal samples. In assigning the bands, the absorption bands are compared with the standard patterns (Scheinman 1970; Speight 1973; Karr 1978a; Given et al 1985; Cooke et al 1986; Grigoriew 1990; Das 2001). The broad absorption bands observed between 3200 and $3600 \mathrm{~cm}^{-1}$ in the coals are due to $\mathrm{N}-\mathrm{H}$ and $\mathrm{O}-\mathrm{H}$ groups. The main features of FTIR are the strong aliphatic absorptions $\left(2920-2850 \mathrm{~cm}^{-1}\right)$. The intensity of peaks at $2920 \mathrm{~cm}^{-1}$ is greater than the peaks at $2850 \mathrm{~cm}^{-1}$ for all the coal samples and indicates the presence of long aliphatic chains in all the coals. The pronounced aliphatic character is connected with their suitability for liquefaction. Low intensity aromatic bands were observed in $900-700 \mathrm{~cm}^{-1}$ regions for Baragolai and Tipong coals. The peaks near to $1699 \mathrm{~cm}^{-1}$ appears in coal indicating the presence of carbonyl $(\mathrm{C}=\mathrm{O})$ contents. The oxygen containing functional groups found in coal specifically include phenols, alcohols, ethers, carboxylic acid and carbonyls. The region of $1000-1300 \mathrm{~cm}^{-1}$ observed in the spectra is for $\mathrm{C}-\mathrm{O}$ bonds

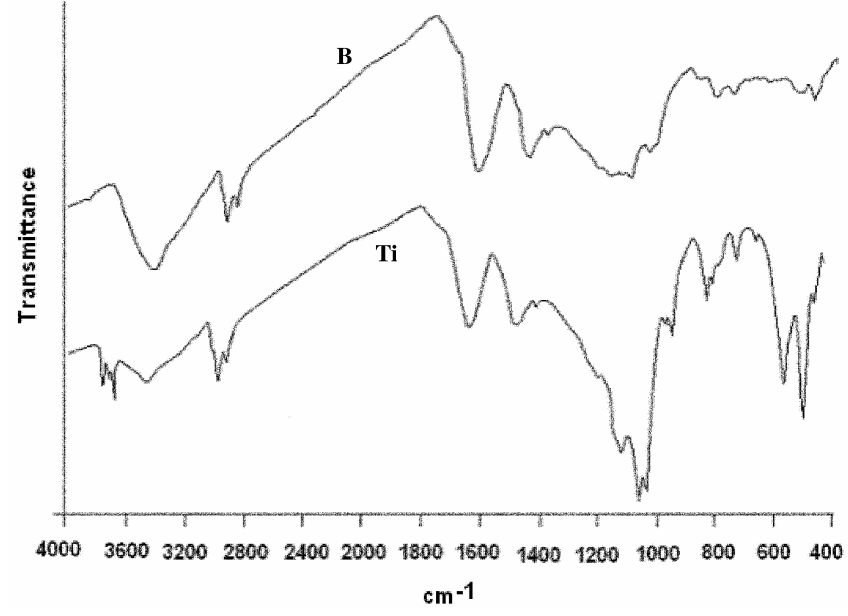

Figure 4. FTIR patterns of the two coal samples (B: Baragolai and Ti: Tipong coals).

in coal structures. The absorbance in this region is found to be decreased in case of Baragolai coal. The weak band at $690 \mathrm{~cm}^{-1}$ observed in the coal may be due to $\mathrm{C}-\mathrm{S}$ bond. FTIR spectra may be used for the identification of minerals associated in the coal structures (Karr 1978a). Most of the peaks in FTIR spectra of coal between 1100 and $400 \mathrm{~cm}^{-1}$ can be assigned to clay minerals such as quartz, kaolinite, illite and montmorillonite groups. The distinct peaks at $1031 \mathrm{~cm}^{-1}$ and $1008 \mathrm{~cm}^{-1}$ are for kaolinite mineral group and $471 \mathrm{~cm}^{-1}$ can be attributed to quartz in the 4 coal samples. A weak absorption due to iron pyrite $\left(\mathrm{FeS}_{2}\right)$ at $420 \mathrm{~cm}^{-1}$ in Tipong coal is also observed. So, the two Assam coals are contaminated with clay minerals, mainly, kaolinite and quartz. The coals studied are found to be similar in mineralogical compositions from XRD and FTIR analyses.

\section{Conclusions}

The two coal samples from Assam are found to be amorphous in nature. Radial distribution function (RDF) study on these coals indicates that they are lignite in type and 
there is no evidence of graphite-like structure. The coals contain aliphatic chains with parallel orientations. The curve intensity profiles obtained from RDF show quite regular molecular packets for this coal. FTIR study shows the presence of aliphatic, aromatic, $\mathrm{C}=\mathrm{O}, \mathrm{C}-\mathrm{O}$ groups and minerals such as kaolinite, quartz etc.

\section{References}

Alvarez A G, Molina-Sabio M and Rodriguez-Reinoso F 1998 Carbon 3667

Barooah P K and Baruah M K 1996 Fuel Process. Technol. 46 85 (references therein)

Baruah B P, Saikia B K, Kotoky P and Rao P G 2006 Energy \& Fuel 201550

Blayden H E, Gibson J and Riley H L 1944 Proc. conf. on ultrafine structure of coals and cokes (London: BCURA) p. 176

Cartz L and Hirsch P B 1960 Proc. R. Soc. (London) A252 557

Cartz L, Diamond R and Hirsch P B 1956 Nature 117500

Cooke N E, Fuller M and Gaikwad R P 1986 Fuel 651254

Das T K 2001 Fuel 80489

Diamond R 1958 Acta Crystallogr. 11129

Elliot Martin A (ed.) 1981 Chemistry of coal utilization, second supplementary volume (New York: John Wiley \& Sons) p. 89

Given P N, Davis A, Kuchn D, Painter P and Spackman W 1985 Int. J. Coal Geol. 5247

Gorbaty M L and Ouchi K 1981 Coal structure (Washington, DC: American Chemical Society) pp 1-2

Grigoriew G 1990 Fuel 69840

Haenel M W 1992 Fuel 711211

Himus G W (ed.) 1954 Fuel testing, laboratory methods in fuel technology (London: Leonard Hill) pp 67-78

Hirsch P B 1954 Proc. R. Soc. (London) A226 143

Iino M 2002 Energy \& Fuel 161
Karr C Jr. 1978a Analytical methods for coal and coal products (New York: Academic Press) Ch. 6, Vol. I

Karr C Jr. 1978b Analytical methods for coal and coal products (New York: Academic Press) Vol. II

Kashimura N, Hayashi J, Li Cz, Sathe C and Chiba T 2004 Fuel 8397

Klug P H and Alexander L E 1974 X-ray diffraction procedure (New York: Wiley Interscience, John Wiley) p. 791

Kruh R F 1962 Chem. Rev. 62319

Mahadevan C 1929 Fuel 8462

Mahadevan C 1930 Fuel 9574

Maity S and Mukharjee P 2006 Curr. Sci. 91337

Marzec A 2002 Fuel Process. Technol. 77-78 25

Myers R A (ed.) 1981 Coal handbook (New York: Marcel Dekker Inc.) pp 1-2

Myers R A (ed.) 1982 Coal structure (New York: Academic Press) p. 8

Mitra G B 1953 Acta Crystallogr. 6610

Nelson J B 1954 Fuel 33381

Ruland W 1968 Chemistry and physics of carbon (ed.) P C Walker Jr. (New York: Marcel Dekker Inc.) Vol. 4, p. 1

Saikia B K, Boruah R K, Baruah B P and Gogoi P K 2005 34th National seminar on crystallography (Guwahati: Gauhati University) p. 63

Scheinman F 1970 An introduction to spectroscopic methods for the identification of organic compounds (Oxford: Pergamon Press) Vol. 1

Schoening F R L 1982 Fuel 61695

Schoening F R L 1983 Fuel 621315

Speight J G 1973 Appl. Spectrosc. Rev. 5211

Vasin I O and Gladyshera G I 1983 Kristallographie 28446

Vogel A I 1969 A textbook of quantitative inorganic analysis, including elementary analysis (New York, London: Longman)

Wertz D L 1998 Fuel 7743

Wertz D L and Bisell M 1994 Energy \& Fuel 8613

Wertz D L and Bisell M 1995 Fuel 741431 